\title{
Running it up the flagpole to see if anyone salutes: A response to Woodward on causal and explanatory asymmetries
}

\author{
(Mandando un globo sonda: \\ una respuesta a Woodward acerca de asimetrias causales y explicativas)
}

\author{
Katrina ElliotT*, MARC LANGE
}

\begin{abstract}
Does smoke cause fire or does fire cause smoke? James Woodward's "Flagpoles anyone? Causal and explanatory asymmetries" argues that various statistical independence relations not only help us to uncover the directions of causal and explanatory relations in our world, but also are the worldly basis of causal and explanatory directions. We raise questions about Woodward's envisioned epistemology, but our primary focus is on his metaphysics. We argue that any alleged connection between statistical (in)dependence and causal/explanatory direction is contingent, at best. The directions of causal/explanatory relations in our world seem not to depend on the statistical (in)dependence relations in our world (conceived of either as frequency patterns or as relations among chances). Thus, we doubt that statistical (in)dependence relations are the worldly basis of causal and explanatory directions.
\end{abstract}

KEYWORDS: explanation; causation; asymmetry; counterfactual; invariance; interventionism; James Woodward.

RESUMEN: ¿El humo causa el fuego, o es el fuego el que causa el humo? James Woodward argumenta en "Flagpoles anyone? Causal and explanatory asymmetries" que varias relaciones de independencia estadistica no solo nos ayudan a descubrir la dirección de las relaciones causales y explicativas, sino que además constituyen el fundamento en el mundo de estas direcciones causales y explicativas. Aunque plantearemos preguntas acerca de la epistemología propuesta por Woodward, nos centraremos en su metafísica. Argumentaremos que cualquier supuesta conexión entre (in)dependencia estadistica y dirección explicativa/causal es en el mejor de los casos contingente. La dirección de las relaciones causales/explicativas en nuestro mundo no parece depender de relaciones de (in) dependencia estadistica en nuestro mundo (concebidas como patrones de frecuencia o como relaciones entre probabilidades). Por tanto, ponemos en duda que las relaciones de (in)dependencia estadistica constituyan la base de las direcciones causales y explicativas.

PALABRAS CLAVE: explicación; causación; asimetría; contrafáctico; invariancia; intervencionismo; James Woodward.

* Correspondence to: Katrina Elliott. Department of Philosophy, University of California, Box 951451, Dodd 321, Los Angeles (CA 90095, United States) - katrina.jeanine.elliott@gmail.com - https://orcid.org/0002-1552-4945

How to cite: Elliott, Katrina; Lange, Marc (2022). «Running it up the flagpole to see if anyone salutes: A response to Woodward on causal and explanatory asymmetriesn; Theoria. An International Journal for Theory, History and Foundations of Science, 37(1), 53-62. (https://doi.org/10.1387/theoria.22351).

Received: 2020-12-16; Final version: 2021-02-17.

ISSN 0495-4548 - elSSN 2171-679X / (C) 2022 UPV/EHU

This work is licensed under a

Creative Commons Attribution-NonCommercial-NoDerivatives 4.0 International License 
We are always excited to see new work from James Woodward, including his recent article, "Flagpoles anyone? Causal and explanatory asymmetries" (Woodward, 2022). In it, Woodward draws epistemological and metaphysical morals about causal and explanatory direction from recent work in statistics and machine learning. Woodward's is a fruitful strategy; he emphasizes the interesting and telling fact that experts reliably infer causal and hence explanatory directions (e.g., that fire causes and explains smoke but that smoke does not cause or explain fire) from three types of statistical independence relations. Here we will ask a few questions about the precise nature of the connection between statistical independence and causal direction that Woodward envisions. Along the way, we will share some of our own thoughts about the worldly underpinnings of causal and explanatory directedness.

Woodward glosses his project as an attempt to "use [an interventionist framework] to try to illuminate some features of explanatory and causal asymmetries" (2022, p. 9). At least some of this light is meant to be cast on the epistemology of explanatory and causal directedness; Woodward introduces his topic with such questions as "Is there some way we can reliably infer, given other assumptions and perhaps information about other correlations... whether the causal direction is from X to Y or from Y to X?" $(2022$, p. 8). Much of Woodward's paper describes techniques (drawn from breakthroughs in statistics and machine learning) for inferring whether $\mathrm{X}$ causes $\mathrm{Y}$ or $\mathrm{Y}$ causes $\mathrm{X}$ (when these are the only epistemically possible causal relations between variables $\mathrm{X}$ and $\mathrm{Y}$ ). The epistemological picture that emerges depicts relative frequencies, analyzed with statistical tools, as providing evidence about the truth of interventionist counterfactuals.

In particular, Woodward holds that statistical independence is evidence of causal independence in at least three ways. First, we should expect causally independent variables also to be statistically independent (CSI). Second, we should expect causal laws to be independent of a system's initial conditions (VRI). Third, we should expect causal relationships to be independent of one another. In addition, whenever some statistical relationships are evidence of causal relationships, those statistical relationships are also evidence of corresponding interventionist counterfactuals.

What is the status of CSI, VRI, and the other putative facts (all of which Woodward introduces collectively as "G" (2022, p. 10)) that Woodward says "we use to correctly infer causal and explanatory direction even if we have not performed the appropriate experimental interventions" (2022, p. 10)? In discussing CSI, VRI, etc., Woodward makes the illuminating point that statistical independence relations play multiple important roles in the epistemology of causal and explanatory direction. We were fascinated to read his descriptions of new techniques for uncovering causal direction from statistical information. However, Woodward also seems to assign a (more controversial) role to these putative facts. He says that they are "more than 'mere heuristics' for inferring causal direction" (2022, p. 12). VRI, for instance, "is not merely a superficial symptom that happens to be associated with causal direction” (2022, p. 40).

That had better be the case, it seems to us, in order for Woodward to be correct in taking himself to be in conversation with pragmatist philosophers who think that "the directional features we ascribe to explanations and causal claims have their source in facts about human psychology" (2022, p. 15). Against this view, Woodward aims to reply by showing that "there are procedures that reliably identify causal direction and that make use of information about how matters stand in the world, rather than information about our interests or about human psychology" (2022, pp. 15-16). This strategy for replying to the pragma- 
tists depends (it seems to us) on taking CSI, VRI, etc., to be facts about what causal relations are, not merely about how we ascertain them. After all, the pragmatists (according to whom it is we who give causation and explanation their directedness) can fully recognize that objective facts about statistical (in)dependence relations track our judgments of causal directedness. The pragmatists can be rebutted only by showing that explanatory and causal directedness consist wholly in facts that are independent of our psychology. Showing that explanatory or causal directedness can be ascertained from facts that are independent of our psychology will not suffice.

Of course, a thoroughgoing empiricist about causal relations will deny even that we are entitled to use CSI, VRI, etc., to ascertain facts about causal direction, insofar as facts about causal direction have modal import (as the interventionist takes them to have). Just as one cannot undermine inductive skepticism by pointing out that evidence concerning the past tracks our common-sense expectations about the future, so likewise one cannot undermine the thoroughgoing empiricist about causal relations by pointing out that evidence about what actually happens (that is, about relative frequencies, statistical independence, and the like) tracks our common-sense expectations about what would have happened had things been different. The inductive skeptic demands to know how it could be that the past is evidence for the future; likewise, the empiricist demands to know how it could be that actual patterns are evidence of counterfactual patterns.

For example, here is a representative passage in which Woodward connects statistical independence to interventionist counterfactuals: "Similarly, looking at the matter from an interventionist perspective, if, as we are assuming, the only two possibilities are that $\mathrm{X}$ and some $U$ cause $Y$ or that $Y$ and some $U^{\prime}$ cause $X$, the existence of a $U$ which is independent of $\mathrm{X}$ but not independent of $\mathrm{Y}$ strongly suggests that one can intervene on $\mathrm{Y}$ (by using $\mathrm{U}$ ) without changing $\mathrm{X}$, which is diagnostic of the absence of a causal relationship from $\mathrm{Y}$ to X” (2022, p. 34) (our italics). The empiricist demands to know why what actually happens "strongly suggests" anything at all about what would have happened, had various things been different. This may be a question that Woodward is simply not aiming to address.

There may be others in the same neighborhood. There are many ways in which each epistemic agent ascertains explanatory and causal relations. Testimony is obviously one way. (Our parents told us that fire causes smoke whereas smoke does not cause fire.) But the content of the testimony we receive is presumably a "merely superficial symptom" of causal directedness. It presupposes other, more direct ways of making these discoveries. In denying that CSI, VRI, etc., are similarly superficial symptoms, Woodward is presumably indicating that there is something deeper about the evidentiary relationship between statistical (in)dependence and explanatory or causal relations than there is about the evidentiary relationship between testimony (for instance) and explanatory or causal relations.

This leaves open several options. One option is that statistical (in)dependence relations are direct evidence regarding causal relations, from which (in turn) we should infer interventionist counterfactuals. Another option is that statistical (in)dependence relations are direct evidence regarding interventionist counterfactuals, from which (in turn) we should infer causal judgements. Another option is that statistical (in)dependence relations are direct evidence regarding some additional features of the world (such as laws or dispositions) that are metaphysically or conceptually linked to both causal relations and interventionist counterfactuals. That the evidentiary relationship between statistical (in)dependence and explanatory or causal relations is prior to the evidentiary relationship between 
testimony (for instance) and explanatory or causal relations seems compatible with all of these options. These epistemological questions about causal directedness are enlivened but not directly addressed by Woodward's paper.

Let's now consider what is supposed to enable CSI, VRI, etc., to underwrite reliable inferences to causal relations. Sometimes it seems as if Woodward regards CSI, VRI, etc. as playing their epistemic roles because of the considerations that make one potential scientific explanation better (in the sense of "inference to the best explanation") than another. For instance, Woodward regards CSI as connected to "the explanatory virtue of avoiding unexplained coincidences" (2022, p. 32) and refers to models with unexplained coincidences as "deficient qua explanations" (2022, p. 29). However, Woodward seems to believe that there are deeper reasons why facts such as CSI play their epistemic roles. VRI, for instance, is intended to tie into Woodward's interventionist/manipulationist account of what causal relations are (a simple version of which is given as (M) on (2022, p. 8)); VRI says roughly that the laws would still have held under twiddles of the causal variables, and that invariance is why "we can use manipulation of $\mathrm{X}$ and the $\mathrm{X} \rightarrow \mathrm{Y}$ relationship as a way of changing $\mathrm{Y}$ " (2022, pp. 40-1). So the origins of VRI and its colleagues are supposed to lie pretty deep. ${ }^{1}$

How deep is unclear. At times, Woodward seems explicit that statistical (in)dependence relations are evidence of causal and explanatory relations in virtue of their metaphysi-

1 VRI also seems to tie into what laws of nature are (according to Woodward), namely, facts that have a broad range of invariance under certain sorts of counterfactual twiddles (Woodward, 2000b). In this respect, Woodward's view of laws is roughly similar to Lange's (2009), though Woodward (2000b, pp. 1912-3) takes pains to point out the differences that (he says) make his view superior. The chief difference he emphasizes is that his account requires that laws remain invariant only under counterfactual twiddles made by interventions, whereas Lange imposes no such limitation and so implausibly (Woodward says) requires laws to be invariant even under a "counterfactual under which we consider whether it is reasonable to infer the truth of the consequent given the supposition of the antecedent." Lange (2009, pp. 198-200), however, discusses these sorts of potential counterexamples to his view and argues that they involve indicative conditionals, not counterfactual conditionals. Counterfactuals, he says, concern whether the consequent would have been true under the antecedent, not whether it is reasonable to infer the truth of the consequent having been told the antecedent's truth. One important difference between Lange's view and Woodward's is that Woodward's treats laws one-by-one, deeming that a given law must have a broad range of invariance. Lange, by contrast, considers the laws collectively, not individually; a law's lawhood (and natural necessity) is a team effort, not an individual achievement. He argues that what distinguishes a law (as far as its invariance under counterfactual antecedents is concerned) is not that it has a broader range of invariance than an accident, but that the laws collectively have as broad of a range of invariance as they could collectively have. Lange's view therefore permits counterfactual antecedents under which a given accident would still have held, but a given law would not still have held (Lange, 2009, pp. 12-13). Lange's view also allows that one actual law would (or, at least, might) have been violated, had some other actual law (with which it stands in no logical relationship) been violated. For instance, had one fundamental kind of physical interaction violated one of the great symmetry principles or conservation laws, then (with that constraint out of the way) some other fundamental kind of interaction might have done so, too. Of course, this is not a counterfactual twiddle made by an intervention. By going beyond counterfactual twiddles made by interventions, Lange (2009) purports to account for the sense (according, e.g., to Wigner) in which certain laws (such as the spacetime symmetry principles and the great conservation laws) transcend other laws (such as the various force laws): the symmetry principles and conservation laws would still have obtained, had there been additional kinds of forces. 
cal connection to causal and explanatory relations. For example, Woodward is critical of metaphysical accounts on which causal directedness is derived from causal laws, such as those found in Davidson (1967) and Armstrong (1997). He argues that we need not look to causal laws to find a worldly source of causal direction, since causal direction is instead based in statistical (in)dependence relations combined with facts such as VRI and CSI:

$[\mathrm{M}] \mathrm{y}$ contrary suggestion is that the basis for the directional features of causation is to be found in facts about initial and boundary conditions characterizing the systems we are analyzing and how these relate to (or interact with) laws and c-generalizations. At least some of these facts are captured by conditions like VRI and CSI. Arguably these conditions involve straightforwardly "objective" facts that describe how matters stand in the world... (2022, p. 42)

Woodward's observations about VRI and CSI could bear on whether laws have causal directedness "built in", so to speak, only if Woodward were making a metaphysical claim about what causal directedness consists in.

Let's now consider what is supposed to explain the truth of VRI, CSI, and the other components of G. Presumably, their truth depends on something to do with what causation and explanation are. Yet Woodward resists characterizing his project as metaphysical:

I said above that the supporting features $G$ are ordinary empirical features of our world. I believe, as an empirical matter, that they are present in many systems in our world but nothing guarantees that they are always present. Still less will these features be present in all logically possible worlds: their presence is not a matter of conceptual truth. One consequence is that my discussion of causal direction is not intended to apply to worlds that are wildly different from our own: For example, I will not attempt to capture "intuitions" some may have about what causal direction amounts to in universes that contain just two particles. Again, to the extent that a metaphysics of causal direction attempts to address questions about what causal direction consists of in all possible worlds this is not my project. (2022, p. 13)

But if VRI, CSI, and the like are not built into what causal and explanatory relations are, then it remains unexplained why they obtain in our world (and so, in turn, it remains unexplained why are they so epistemically useful). Furthermore, if there is directionality without VRI, etc., in some possible worlds, then why is directionality based on VRI, etc., in the actual world? If there is directionality without VRI, etc., in some possible worlds, then why isn't the "basis" of directionality in those worlds available to be its basis in the actual world?

Woodward says, "I don't think of the ideas that follow as a contribution to the kind of metaphysics that purports to tell us what causation is" (2022, p. 12). Yet he seems at least to entertain the possibility of their making such a contribution. (Their doing so would nicely short-circuit questions like those we asked just above.) Expressing reluctance to incorporate CSI, etc., into what causal relations are, Woodward writes:

Let me repeat that my claim is that CSI describes a generic pattern that, as a contingent empirical matter holds widely, if not universally, in our world. I do not claim that CSI reflects a conceptual or metaphysical truth of some kind that holds in "all possible worlds". My assumption is that CSI and similar principles, although contingent, help to underpin the ways in which we think about causation and causal direction. (They are part of the infrastructure associated with causal direction mentioned earlier.) I will not speculate about how if at all one thinks about causal direction in worlds in which CSI is systematically violated (or which we might find it tempting to describe in that way). (2022, p. 23) 
But what if CSI, etc., are violated? Is the directionality of causal relations then secured by some other means, rather than by facts like CSI, etc.? If CSI, etc., are metaphysically necessary for there to be causal relations, then the problem of what makes for causal relations' directionality without CSI, etc., cannot arise.

In a footnote to the above passage, Woodward seems to recognize this as a possible solution. Regarding "how if at all" (our emphasis) we should "think about causal direction in worlds in which CSI is systematically violated (or which we might find it tempting to describe in that way)," Woodward writes: "Of course if the way in which we think about causation is not applicable to such cases, it presumably doesn't make literal sense to describe them in terms of violations of CSI which is a claim about how causation, as we think about it, is connected to probability" (2022, p. 23, fn. 32). If CSI, etc., are metaphysically or conceptually required by causal relations, then worlds that "we might find it tempting to describe" as violating CSI (i.e., as worlds where there are causal relations that are not connected to statistics in the manner required by CSI) are worlds without causal relations at all and so (trivially) satisfy CSI.

It seems like worlds could violate CSI. ${ }^{2}$ What this would require depends somewhat on how CSI is to be understood. CSI requires the statistical independence of causally independent variables. This seems to mean that for causally independent variables $\mathrm{H}$ and $\mathrm{A}$, a given value of $\mathrm{H}$ is as frequently associated with one value of $\mathrm{A}$ as with any other. This is the way that statistical independence is elaborated in the flagpole case (where $\mathrm{H}$ is the height of the flagpole, $\mathrm{A}$ is the angle to the ground of the light source shining on the flagpole, and $S$ is the length of the flagpole's shadow on the ground):

Suppose that we observe several flagpoles of different fixed heights $h_{1} \ldots h_{n}$, at different times of day for each pole, so that $A$ varies. In this case for any given $A$, there will be a correlation between the heights of the poles and the corresponding shadows of lengths $s_{1} \ldots s_{n}$ but no correlation between $H$ and $A$. (2022, p. 26)

Statistical independence, then, seems to be purely a matter of frequencies-of lack of "correlation". So understood, though, CSI would seem to preclude fluky, purely coincidental, unlikely correlations among causally independent variables. But Woodward says otherwise: "Note that [CSI] doesn't mean that 'coordinated' behavior among independent causes on particular occasions is impossible; rather it means that the probability of this occurring is low, for the same reason that a long run of heads in a series of causally and statistically independent coin flips is possible but unlikely" (2022, p. 22, fn. 29). We are not sure why CSI's official statement permits such a fluke.

Of course, there is a motivation to interpret CSI as permitting such a fluke. If such a fluke undermined CSI's application to a given case, then causal directionality in that case could not depend on CSI. But the occurrence of such a fluke would presumably leave unaltered the usual directions of causal relationships. For instance, suppose that someone blew up various flagpoles over the course of a day in such a way that coincidentally, $\mathrm{H}$ and $\mathrm{A}$ for flagpoles when we observed them ended up being correlated. Then the directions of the

2 Perhaps the same case cannot be made that some possible worlds violate VRI. See the previous note, which discusses the (seemingly metaphysically necessary) connection between lawhood and some special sort of invariance under counterfactual twiddles. 
causal relationships among $\mathrm{H}, \mathrm{S}$, and A would presumably be no different. But that directionality couldn't then be based on CSI. This result suggests (at least to some degree) that even when CSI obtains, directionality isn't based on CSI.

If CSI is interpreted as concerning objective chances rather than frequencies, then CSI permits such flukes; obviously, such a fluke correlation would not undermine the variables' statistical independence understood in terms of their objective chances. Nevertheless, it seems (pretheoretically, at least) that there are possible worlds where CSI (in terms of chances) is violated (not because of some fluke correlation-which, as just noted, wouldn't be enough to violate it) and yet causal directionality obtains in its usual way, presumably for its usual reasons. Presumably as well, this is precisely the sort of "intuition" about "worlds that are wildly different from ours" that Woodward disparages in a passage quoted above and says that he is not trying to capture. But if causal directionality is maintained in such worlds even without CSI (let's say), then doesn't that fact potentially count (at least to some degree) against CSI's being crucial to causal directionality in the actual world?

There are doubtless more compelling examples where CSI (as so interpreted) fails, but a simple one might consist of a possible world where there are two kinds of particles ( $\mathrm{p}$-ons and q-ons). There are laws giving each particle's effects on the trajectories of other particles near it. For a given special location, there is a law specifying the chance that a p-on will spontaneously come into existence there at the end of each ten-second interval (starting now...). There is another law specifying the chance that a q-on will spontaneously come into existence at another special location at that same moment. By these laws, these chances vary for different intervals, but the p-on chance and q-on chance are correlated. These two potential causes (the popping into existence of a p-on and the popping into existence of a q-on at the two special locations) are thus causally independent but statistically dependent. The causal directionality of the effects of these particles seems unaffected by this violation of CSI. ${ }^{3}$

It thus does not seem plausible to us that the worldly basis of causal and explanatory directionality is to be found in statistical relations or relations among chances. In fact, perhaps a genuine interventionist ought to resist locating the worldly basis of causal and explanatory directionality in statistical relations (or relations among chances), VRI, and G's other components. For an interventionist, the worldly source of causal and explanatory directionality should be whatever makes true the relevant interventionist counterfactuals. What makes it the case that fire causes smoke but smoke does not cause fire, for example, should be whatever makes it the case that intervening on fire's presence would make a difference to smoke's presence but not vice versa. Woodward astutely makes this point himself but goes on to worry that an interventionist treatment of causal directedness will be unsatisfying because "the notion of an intervention is of course itself a causal notion and as such has a notion of causal direction built into it" (2022, p. 10). We agree that that is a concern. But we wonder whether this concern can be plausibly met by tying causal directedness to (at best) contingent facts such as VRI and CSI. Just as causal and explanatory directionality seem unaffected by violations of CSI, so too the truth-values of the relevant interventionist counterfactuals seem unaffected by violations of CSI.

Woodward's paper concludes by considering the Königsberg bridge example. Euler arguably explained why no one ever succeeded (or, in particular, why a given person never

\footnotetext{
3 Our debt to Sober (2001) here should be obvious.
} 
succeeded) in crossing all of the bridges of Königsberg (as they were arranged in 1735) exactly once (while remaining always on land or on a bridge rather than in a boat, for instance, and so forth). Euler discovered that a network is "traversible" in this sense if and only if either every vertex or every vertex but two is touched by an even number of edges. (Any successful bridge-traverser would have to enter a given vertex exactly as many times as she leaves it, unless the vertex is the start or the end of her trip. So among the vertices, either none (if the trip starts and ends at the same vertex) or two could touch an odd number of edges.) Arguably, then, the reason why no one ever succeeded at traversing the Königsberg bridges is that this arrangement of bridges possesses a certain graph-theoretic feature. Woodward is concerned with the directionality of this putative non-causal explanation of the bridge arrangement's non-traversibility by the bridge arrangement's possessing the graph-theoretic feature that Euler uncovered. In particular, an explanation runs from the arrangement's graph-theoretic feature to the arrangement's non-traversibility, but not in the reverse direction.

The discussion in Woodward's paper (2022, pp. 47-8) appears to focus exclusively on what justifies our belief regarding this directionality (e.g., "this two explanation story...was less plausible", "it is reasonable to conclude...", "in the absence of some further explanation of these dependencies, we should infer that the direction...", etc.). His idea is that "the intentions and behavior of those who constructed the bridges" (2022, p. 47) caused the graph-theoretic feature. Therefore, for the bridges' non-traversibility also to explain (noncausally) the graph-theoretic feature would involve the graph-theoretic feature's implausibly having two explanations, where the two explainers (the builders' intentions/behavior and the arrangement's non-traversibility) "just happen to be correlated even though no explanation is provided for this fact” (2022, p. 48).

However, an interventionist treatment of causation seems to imply that the intentions and behavior of the builders caused the bridges to be arranged so as to possess Euler's graph-theoretic feature and caused the bridges to be non-traversible. The graph-theoretic feature and the non-traversibility stand and fall together, by necessity. So if interventions on the intentions/behavior of the builders are associated with changes in whether the bridge's arrangement has Euler's graph-theoretic feature, then these same interventions are also associated with changes in whether the bridge arrangement is traversible. Thus, whether the graph-theoretic feature (non-causally) explains the non-traversibility or the non-traversibility explains the graph-theoretic feature, we will have both a non-causal and causal explanation of one of the bridge arrangement's features. Furthermore, whichever way the non-causal explanation runs, we will not have any unexplained correlations on our hands. Both the non-traversibility and the graph-theoretic feature are correlated with the intentions/behaviors of the builders, and the intentions/behaviors of the builders also causally explains both the non-traversibility and the graph-theoretic feature.

But let's set the above worry aside since these all appear to be epistemic matters; they do not obviously concern what makes the bridges' non-traversibility explained (non-causally) by the arrangement's graph-theoretic feature rather than the reverse. That certain considerations justify our belief about the directionality fails to show that "this directionality could be understood" (2022, p. 47) in terms of these considerations. In other words, even if "the putative explanation of $E$ [the graph-theoretic feature] in terms of $T$ [non-traversibility] seems redundant and superfluous [both!], given the availability of an explanation [of $E$ ] in terms of $X$ [the intentions/behavior]" (2022, p. 48, fn. 72 ), we doubt whether 
that redundancy is what makes it false that non-traversibility non-causally explains the arrangement's graph-theoretic feature. ${ }^{4}$

Rather, the existence of a causal explanation (appealing to the builders' intentions/behavior) of the bridge arrangement's graph-theoretic feature may play solely an epistemic role: of helping justly to persuade us that non-traversibility fails to non-causally explain the arrangement's graph-theoretic feature. Indeed most accounts of scientific explanation regard a given candidate as qualifying or not as a genuine explanation for reasons having nothing to do with what other explanations there happen to be. ${ }^{5}$

As an illustration, here is an example (from Lange, 2019) that involves precisely the relation between causal and non-causal explanations. Consider a rocket (feeling negligible gravitational influences) consisting primarily of a chamber filled with gas that can serve as fuel, a mechanism for igniting the gas (suddenly increasing its temperature and pressure), and a valve on the left side of the chamber (that is, a wall that can be removed by some means requiring negligible force and making negligible contribution to the system's momentum). Suppose that the rocket is initially at rest and then the gas is ignited. The rocket remains at rest with the high-pressure gas inside until the valve is opened. When that happens, gas escapes to the left as exhaust while the rocket accelerates to the right.

A genuine explanation of the rocket's acceleration to the right, when the valve on the left is opened, is causal-mechanical: with the valve opened, the gas molecules in the rocket exert greater force on the right-hand wall than on the left-hand wall, since the valve on the left is open so there is less wall on the left than on the right for the gas to hit. The internal force is therefore unbalanced, pushing the rocket to the right. One might be tempted to think that there is also a non-causal, momentum-conservation-law explanation of the rocket's rightward acceleration: the exhaust has leftward momentum, so momentum conservation requires that the rocket have rightward momentum. Lange (2019) argues that this momentum-conservation argument is not in fact explanatory-at least, not for the very same explanandum as the causal-mechanical explanation targets (namely, the fact that the rocket accelerates to the right, rather than remaining at rest or accelerating to the left). But (on Lange's view) it is not the existence of the causal-mechanical explanation that makes the momentum-conservation argument non-explanatory. Rather, what makes the momentum-conservation argument non-explanatory is that it would have to use the exhaust's accelerating leftward as part of what explains the rocket's accelerating rightward, but there is nothing to make the exhaust's moving to the left explanatorily prior to the rocket's moving to the right. (Nor does anything make the reverse qualify as the order of explanatory priority.)

The same applies in the case of the bridges. For their non-traversibility to explain their possessing a certain graph-theoretic feature (or vice versa), some consideration relevant to

4 For that matter, why doesn't the same argument apply to the putatively correct direction of non-causal explanation? Why doesn't the putative explanation of the arrangement's non-traversibility by the arrangement's graph-theoretic feature seem redundant given the availability of an explanation of the arrangement's non-traversibility by the builders' intentions/behavior?

5 Kitcher's (1989) account is a notable exception. On his view, an argument's status as an explanation depends on its argument pattern earning its way into the explanatory store, which depends on its covering explananda that have not already been covered by the store's members (or its covering explananda that have already been covered by the store's members, but covering them in a more stringent way, or...). 
non-causal explanatory priority would have to make non-traversibility explanatorily prior to the graph-theoretic feature (or vice versa). Whether some such consideration exists would seem to have nothing to do with whether there is a causal explanation of the graphtheoretic feature (or the non-traversibility).

To conclude: Woodward's paper paints an interesting and attractive picture of the epistemology of causal and explanatory direction. We would be interested to hear even more, such as how Woodward thinks interventionists should address skeptical empiricist challenges about counterfactuals or what separates the epistemological role of CSI, VRI, etc., from comparatively superficial symptoms of causal relations (e.g., testimony). Turning to Woodward's more metaphysical inquiries, we doubt that explanatory and causal relations owe their directionality to the kinds of statistical patterns or relations among chances that Woodward identifies. But we readily admit that we may have missed Woodward's point in this portion of his discussion. He emphasizes that his project should be interpreted neither merely as epistemology nor as metaphysics in the sense that many philosophers understand it. He says that it is instead associated with "minimal metaphysics" (2022, p. 11, fn. 8). We look forward very much to hearing more about that.

\section{REFERENCES}

Armstrong, D. (1997). A world of states of affairs. Cambridge: Cambridge University Press.

Davidson, D. (1967). Causal relations. Journal of Philosophy, 64, 691-703.

Kitcher, P. (1989). Explanatory unification and the causal structure of the world. In P. Kitcher \& W. Salmon (Eds.). Scientific explanation (pp. 410-505). Minneapolis: University of Minnesota Press.

Lange, M. (2009). Laws \& lawmakers. New York: Oxford University Press.

Lange, M. (2019). Are there both causal and non-causal explanations of a rocket's acceleration?. Perspectives on Science, 27, 7-25.

Sober, E. (2001). Venetian sea levels, British bread prices, and the principle of the common cause. British Journal for the Philosophy of Science, 52, 331-346.

Woodward, J. (2020). Physical modality, laws, and counterfactuals. Synthese, 197, 1907-1929.

Woodward, J. (2022). Flagpoles anyone? Causal and explanatory asymmetries. THEORIA: An International Journal for Theory, History and Foundations of Science, 37(1), 7-52 (https://doi.org/10.1387/ theoria.21921

Katrina Elliotr is Assistant Professor of Philosophy at the University of California, Los Angeles. She works at the intersection of philosophy of science and metaphysics.

AdDress: Department of Philosophy, University of California, Box 951451, Dodd 321, Los Angeles, CA 90095, United States.

E-mail: katrina.jeanine.elliott@gmail.com

ORCID: 0000-0002-1552-4945

Marc Lange is Theda Perdue Distinguished Professor of Philosophy at the University of North Carolina at Chapel Hill. His research concerns central topics in the philosophy of science. His latest book is Because Without Cause (Oxford University Press, 2017).

Address: Department of Philosophy, University of North Carolina, CB\#3125, Chapel Hill, NC 2759903125, United States.

E-mail: mlange@email.unc.edu

Website: https://philosophy.unc.edu/people/marc-lange/

ORCID: 0000-0002-0704-7376 